\title{
Correlations for Double Flow Double Pass SAH with Smooth Absorber Plate
}

\author{
Mohitkumar G. Gabhane* and A. B. Kanase-Patil \\ Department of Mechanical Engineering, Sinhgad College of Engineering, Pune-41, India \\ Accepted 15 June 2016, Available online 20 June 2016, Special Issue-5 (June 2016)
}

\begin{abstract}
Solar Air Heater (SAH) provides the efficient use of solar energy, which uses absorber plate to absorb incoming solar radiation, converting it to thermal energy and transfers thermal energy to fluid flowing through it. By making SAH double pass, heat transfer rate is enhanced. The method of using Artificial Roughness (AR) on absorber plate is best option to increase heat transfer rate significantly and gives better results than any other method. For good thermohydraulic performance, double flow-double pass arrangement is used. This investigation presents correlations for double flow-double pass SAH having smooth aluminum plate as absorber. Correlations are developed for Nusselt number, Friction factor, Stanton number and Thermohydraulic efficiency. These parameters are help to know overall performance of SAH. Correlations are based on Experimental and CFD simulation data values. Reynolds number is varied from 3000 to 15000. Least square method is used to developed correlations. All correlations are validated by comparing with CFD and experimental values respectively. These correlations are found to predict the experimental results with reasonable accuracy.
\end{abstract}

Keywords: Convective heat transfer, Double pass SAH, Correlations, Smooth absorber plate, Least square method.

\section{Introduction}

${ }^{1}$ Solar Air Heater (SAH) is one of the important equipment through which solar energy is converted into thermal energy. The SAH has an important place among flat-plate solar collectors. It is used as subsystem in many systems for efficient utilization of solar energy. Possible applications of SAH are drying of agricultural products, space heating in Heating Ventilation and Air Conditioning (HVAC) system, seasoning of timber, curing of plastics etc (Karwa et al, 2001). In general, SAH is quite suitable for low and moderate temperature applications as their design is simple and less costly. Also, direct use of air as the working fluid reduces the number of mountings and accessories required in the system.

The thermal performance of a conventional SAH is actually poor because of low convective heat transfer coefficient between air and the absorber plate (Jaurker et al, 2006). The low value of heat transfer coefficient is because of presence of a viscous sub-layer adjacent to absorber plate surface. Viscous sub-layer needs to be broken down for efficient heat transfer from the absorber plate to the air flowing through it. SAH has attracted the attention of a large number of investigators to overcome this problem. Several

*Corresponding author: Mohitkumar G. Gabhane designs of SAH have been developed over the years in order to improve their performance. To increase heat transfer from absorber plate to air streams, double pass arrangement is used. In this arrangement, air gets in contact with absorber plate from both sides which contribute in more extraction of heat from absorber plate. Inlet air is divided into two streams and it is allowed to flow above and below the absorber plate (Dhiman et al, 2012). Flow arrangement of double flow-double pass SAH is shown in Figure 1.

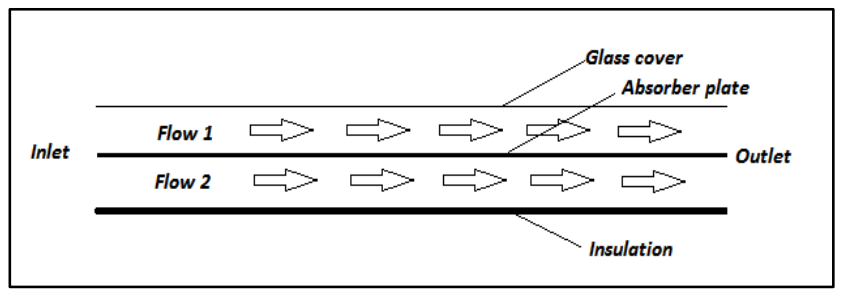

Fig.1 Flow arrangement of double flow-double pass SAH

This type of SAH is used when large amount of moderate heated air is required. Because of division of inlet air into two air stream, thermal extraction is more than that of single flow SAH. The parallel flow system achieved 10\% higher thermohydraulic efficiency (Dhiman et al, 2012). 
For the results to be useful for designer, general correlations are needed to be developed (Bhagoria et $a l, 2002)$. Each design of SAH has its own operating or influencing parameters. Correlations were developed by considering these parameters. Parameters which are strong function for any change in SAH performance need to be chosen. Previous studies shows numbers of correlations on single pass SAH with different shaped artificial roughness on absorber plate. Multiple Vshaped correlations were developed by Hans et al, gives maximum of $10 \%$ of average deviation for all the readings (Hans et al, 2010). Similar type of study on Single pass SAH using rib grooved artificial roughness (Bhagoria et al, 2002) shows average deviation of $\pm 15 \%$ for both the correlations. For developing correlations, regression analysis was used to fit a straight line on a log-log graph.

\section{Experimental setup}

Double flow-double pass SAH is used for the experiment reading which have two flows inside the duct. Dimensions of test rig are as per American Society of Heating, Ventilation and Air Conditioning Engineers (ASHRAE) standards (Saini and Saini, 2008, HO et al, 2013). Aspect ratio of each duct is maintained as 10. Length of inlet section, test section and exit section are 500, 1100 and $250 \mathrm{~mm}$ respectively. Parameters encompassed Reynolds number ranging from 3000 to 15000 (5 steps). 8 number of thermocouples are used to take readings of temperature at various location namely temperature of inlet air ( 2 nos.), temperature of absorber plate ( 4 nos.) and temperature of outlet air (2 nos.). Readings are taken from 10.00 to $15.00 \mathrm{hr}$. at $00.30 \mathrm{hr}$. interval of time. Eleven readings are taken daily for each Reynolds number. These reading are then averaged to obtain a unique average value of temperature. From these readings value of Nusselt number, friction factor and different efficiencies are found and using these values correlations are developed. Experimental setup is shown in Figure 2.

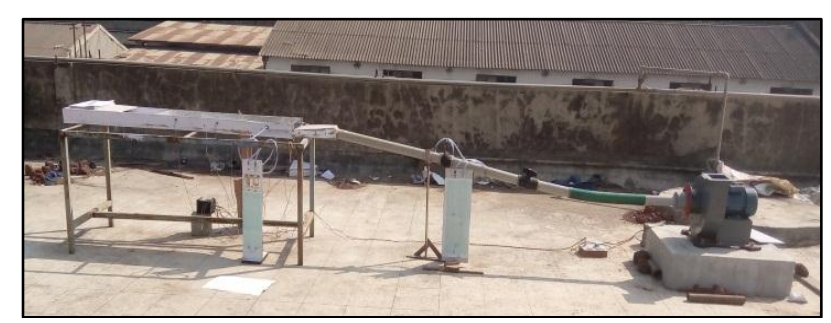

Fig.2 Experimental setup

Experimental setup is designed and fabricated to study the effect of heat transfer and fluid flow characteristics of double flow-double pass SAH. The schematic diagram of experimental setup is as shown in Figure 3. It consists of an absorber duct having (1) as air inlet section (500 $\mathrm{mm}),(2)$ as test $\operatorname{section}(1000 \mathrm{~mm})$ and (3) exit section (250 mm), absorber plate, plenum, pipe, orifice plate, flexible pipe, flow control valve, motor and blower.

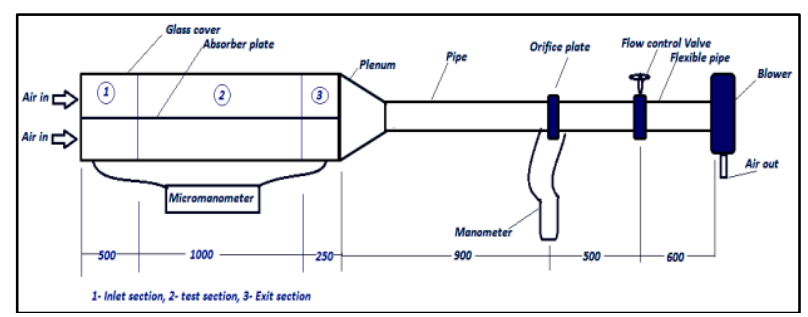

Fig.3 Schematic diagram of experimental setup

The test section consists of rectangular duct having smooth absorber plate for absorbing the solar radiation. Absorber plate divides the inlet air into two flow streams from both sides of absorber plate is made of aluminium which has high thermal conductivity. Thickness of absorber plate is $1 \mathrm{~mm}$. Plenum is used to reduce convergent losses. Control valve is used for flow control. The pressure drop is measured by micromanometer which filled with kerosene and methyl alcohol. The mass flow rate is measured by orifice meter with inclined manometer. The centrifugal blower is used for air supply which has 1 H.P. capacity is used to draw the ambient air into the collector through the entrance section. Absorber plate has roughness geometry from both the sides. The test sections have identical length of $1 \mathrm{~m}$. The width and depth of collector is $0.3 \mathrm{~m}$ and $0.06 \mathrm{~m}$ respectively. Thermocouples are used for measuring the temperature at various locations. Thermocouples are connected to digital temperature indicator. Air is flowing over roughened absorber plate from both the sides of absorber plate so that the heat is transferred to the air. The upper surface of absorber on which the solar radiation falls is coated with black paint. The duct is insulated by plywood of $10 \mathrm{~mm}$ thickness and upper surface is covered with transparent glass which is $4 \mathrm{~mm}$ thick.

\section{Validation of experimental set-up}

For flow inside the duct, Nusselt number and friction factor are obtained by Dittus-boelter equation and Modified Blasius Equation respectively (Thakur et al, 2003).

For $n$ number of flows, equation is multiplied by $n$, i.e. Dittus-Boelter equation for double pass SAH is,

$\mathrm{Nu}=2 \times 0.023 \mathrm{Re}^{0.4} \operatorname{Pr}^{0.8}$

Similarly Friction factor for double pass $\mathrm{SAH}$ is obtained by Modified Blasius Equation,

$\mathrm{f}=2 \times 0.085 \mathrm{Re}^{-0.025}$

Comparison of predicted, experimental and CFD Nusselt number is shown in Figure 4. 
Results shows monotonically increase of Nusselt number with increase in Reynolds number.

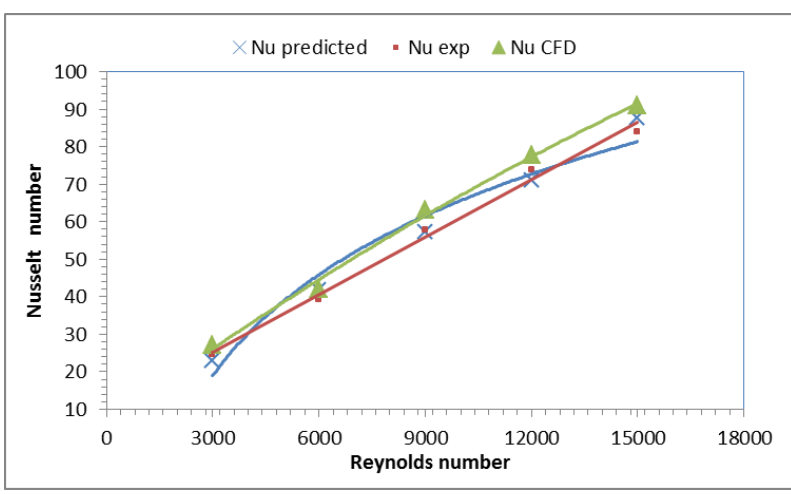

Fig.4 Comparison of predicted correlation, experimental and CFD Nusselt number

Using above equation, maximum deviation between experimental readings and predicted correlation was found to be $8.73 \%$ whereas average deviation was $4.91 \%$ which is less than $10 \%$, hence acceptable.

\section{CFD analysis}

For this investigation, Modeling of 3D model is done using CATIA V5. Model dimensions and material is as follows; Absorber plate length is $1000 \mathrm{~mm}$, absorber plate material is taken as aluminium for maximum conductivity. Inlet duct length is $500 \mathrm{~mm}$, Outlet duct length is $250 \mathrm{~mm}$, absorber plate thickness is $1 \mathrm{~mm}$, wall boundaries thickness is $10 \mathrm{~mm}$. Dimensions is as per ASHRAE standard 1977-93. Wall boundary material is taken as wood for maximum insulation. Glass cover thickness is $4 \mathrm{~mm}$. Simulation model is shown in Figure 5.

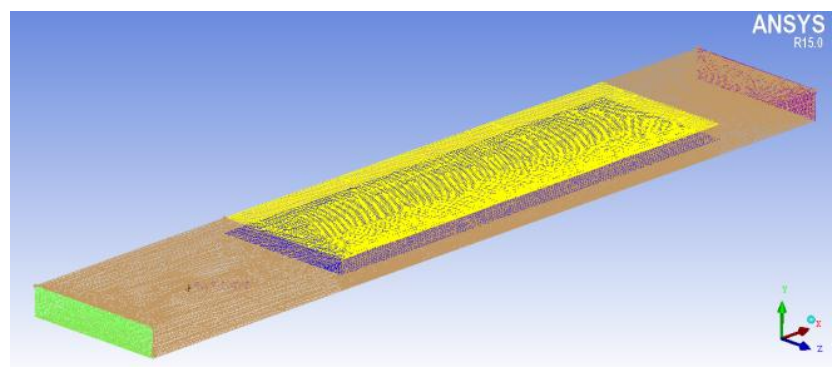

Fig. 5 CFD model of SAH duct

Model is then converted into STEP/IGS format for importing in ICEM CDF 16.0 software. ICEM CFD was used as pre-processor. There was need to place very fine mesh of the absorber plate. Quality of the mesh was checked and it was found in acceptable limit, i.e. above 0.3. The boundaries and continuum as inlet, outlet, heated wall, insulated wall and the fluid zones were defined as per the experimental conditions. The whole geometry was exported so that it accessible in Fluent 15.0. It is basically called a postprocessor for analyzing the CFD problems.
As the flow have high velocity and turbulent, $\mathrm{k}-\varepsilon$ model was selected as turbulent model for further analysis of the problem. Energy equation is also kept in $\mathrm{ON}$ position as a heat transfer model. Air was selected as working fluid with its standard properties. The different boundary conditions for the geometries were selected as: air inlet velocities from $0.447 \mathrm{~m} / \mathrm{s}$ to 2.682 $\mathrm{m} / \mathrm{s}$, outlet pressure as zero gauge pressure.

Table 1 Computational analysis

\begin{tabular}{|c|c|}
\hline Pre-processor & ICEM-CFD 15.0 \\
\hline Solver & Fluent \\
\hline Post-processor & CFD-Post \\
\hline Domain & Pressure-Based \\
\hline Solver & Steady \\
\hline Time & $\begin{array}{c}\text { Energy, RNG } k-\varepsilon \text { model, } \\
\text { Radiation model }\end{array}$ \\
\hline Model & SIMPLE \\
\hline Solution method & Air \\
\hline Fluid & Standard wall function \\
\hline Near wall treatment & Ideal gas \\
\hline Density & Aluminium \\
\hline Plate material &
\end{tabular}

For radiation model, solar ray tracking is used using longitude and latitude of Sinhgad College campus, Pune. As the absorber plate was being heated from one side, the boundary condition for the wall was having uniform temperature of $313 \mathrm{~K}$. All the other walls were considered to be completely insulated with zero heat flux. No slip condition is applied to all the walls.

According to the models selected, the equations which were considered for the solution are continuity equation, energy equation, momentum equation and equation for turbulence. The above equations have been solved under-relaxation factors. After setting all necessary input conditions the problem was iterated for 1000 iterations within which it gives well converged solution so that accurate results were displayed.

\section{Correlation for experimental Nusselt number}

If flow is considered as incompressible then,

$\mathrm{Nu}=\mathrm{f}(\mathrm{Re})$

Step 1- General correlation by least square method. It is seen that Nusselt number is strong function of flow characteristics like Reynolds number. Experimental and CFD simulation data collected and operating parameters are chosen to develop relationship in the form of correlations. To obtain function relationship between Nusselt number and Reynolds number, least square method is used and develop relationship between these parameters for forced convective heat transfer has been utilized (Hans et al, 2010).

$\mathrm{Nu}=\mathrm{b} \mathrm{Re}^{\mathrm{m}}$ 
Also,

$\mathrm{b}=\frac{\mathrm{Nu}}{\mathrm{Re}^{\mathrm{m}}}$

Step 2- obtaining value of slope ' $m$ ' and ' $b$ ' $\mathrm{m}=\frac{\mathrm{n}\left(\sum \mathrm{XY}\right)-\left(\sum \mathrm{X}\right)\left(\sum \mathrm{Y}\right)}{\mathrm{n}\left(\sum \mathrm{X}^{2}\right)-\left(\sum Y^{2}\right)}$

Weget $\mathrm{m}=0.7849$

Least square method is used to develop the correlation between influencing parameters. A statistical method is used to determine a line of best fit by minimizing the sum of squares created by a mathematical function. Initially correlation is developed by choosing one dependent variable and other is independent variable.

Step 3- Find out value of Correlation coefficient (b) using value of slope of line,

$\mathrm{b}^{*}=\frac{\sum \mathrm{Y}}{\mathrm{n}}-\frac{\mathrm{m} \times \sum X}{\mathrm{n}}$
Also,

$\mathrm{b}=\mathrm{e}^{\mathrm{b}^{*}}$

Obtaining $b=-3.1041$

Step 4-Putting values of $m$ and $b$, we get the values of following equation (4), we get

$\mathrm{Nu}=0.04486 \mathrm{Re}^{0.7849}$

Step 5- Validation of correlation

Correlations are validated by comparing the experimental data to the values predicted by correlations.

Similarly steps are followed to develop correlations of Table 1 for Nusselt number, friction factor, Stanton number and thermohydraulic efficiency.

All developed correlations are reported in table 1. For all developed correlations, average deviations are less than $13.375 \%$ which is less than $15 \%$ hence all correlations are under acceptable limit.

Table 2 Correlations for double flow-double pass SAH

\begin{tabular}{|c|c|c|}
\hline \multirow{2}{*}{ Parameters } & \multicolumn{2}{|c|}{ Incompressible Flow } \\
\hline & Experimental & CFD \\
\hline $\mathrm{Nu}=\mathrm{f}(\mathrm{Re})$ & $\begin{array}{l}\mathrm{Nu}=0.04486 \mathrm{Re}^{0.7849} \\
\text { Average deviation }=4.3875 \%\end{array}$ & $\begin{array}{l}\mathrm{Nu}=0.04965 \mathrm{Re}^{0.7752} \\
\text { Average deviation=1.3948\% }\end{array}$ \\
\hline $\mathrm{f}=\mathrm{f}(\mathrm{Re})$ & $\begin{array}{l}\mathrm{f}=0.25922 \mathrm{Re}^{-0.28173} \\
\text { Average deviation }=2.08 \%\end{array}$ & $\begin{array}{c}\mathrm{f}=0.18022 \mathrm{Re}^{-0.24597} \\
\text { Average deviation }=0.77 \%\end{array}$ \\
\hline $\mathrm{St}=\mathrm{f}(\mathrm{Re}, \mathrm{Nu})$ & $\begin{array}{c}\mathrm{St}=0.0621 \mathrm{Re}^{-0.21361} \\
\text { Average deviation }=3.20 \% \\
\mathrm{St}=0.0534 \mathrm{Re}^{-0.214} \mathrm{Nu}^{0.026} \\
\text { Average deviation }=5.91 \%\end{array}$ & $\begin{array}{c}\mathrm{St}=0.0387 \mathrm{Re}^{-0.23} \\
\text { Average deviation }=4.01 \% \\
\mathrm{St}=0.0138 \mathrm{Re}^{-0.23} \mathrm{Nu}^{-0.29} \\
\text { Average deviation }=13.375 \%\end{array}$ \\
\hline $\mathrm{n}^{\text {th }}=\mathrm{f}(\mathrm{Re}, \mathrm{Q}, \mathrm{I})$ & $\begin{array}{c}\eta_{t h}=0.18428 \mathrm{Re}^{0.5826} \\
\text { Average deviation }=6.80 \% \\
\eta_{t h}=0.6023 \mathrm{Q}^{0.9089} \\
\text { Average deviation }=2.7928 \% \\
\eta_{t h}=7.6430 \times 10^{-20} \mathrm{Q}^{0.9089} \mathrm{1}^{6.6418} \\
\text { Average deviation }=2.8581 \% \\
\eta_{t h}=0.1616 \mathrm{Re}^{0.5826} \mathrm{Q}^{0.0293} \\
\text { Average deviation }=6.79 \% \\
\eta_{t h}=1966523 \operatorname{Re}^{0.5826} \mathrm{Q}^{0.0293} \mathrm{I}^{-2.49} \\
\text { Average deviation }=6.8 \%\end{array}$ & $\begin{array}{c}\eta_{t h}=0.2936 \mathrm{Re}^{0.53421} \\
\text { Average deviation }=5.29 \% \\
\eta_{t h}=0.6022 \mathrm{Q}^{0.909} \\
\text { Average deviation }=2.8 \% \\
\eta_{t h}=7.63 \times 10^{-20} \mathrm{Q}^{0.909} \mathrm{I}^{6.65129} \\
\text { Average deviation }=1.92 \% \\
\eta_{t h}=0.3522 \mathrm{Re}^{0.56129} \mathrm{Q}^{-0.01} \\
\text { Average deviation }=4.8431 \%\end{array}$ \\
\hline
\end{tabular}

\section{Conclusion}

From this study following points are summarized,

1) Double pass SAH is more efficient than conventional SAH. By making SAH double pass, thermohydraulic efficiency get enhanced.

2) Experimental results were validated by Dittusboelter equation and modified Blasius equation for Nusselt number and friction factor respectively.
3) Correlations are developed by using influencing parameters only.

4) It is seen that percentage deviations for all the correlations developed are within acceptable limit, which is below $15 \%$, hence all correlations are under acceptable limit.

5) By developing correlation, usefulness of study gets increased which helps in further research in this field. 
6) No correlations were found on double pass $\mathrm{SAH}$ having artificial roughness, hence there is large scope for doing further research in this domain.

Validation graphs of above correlations are presented below,

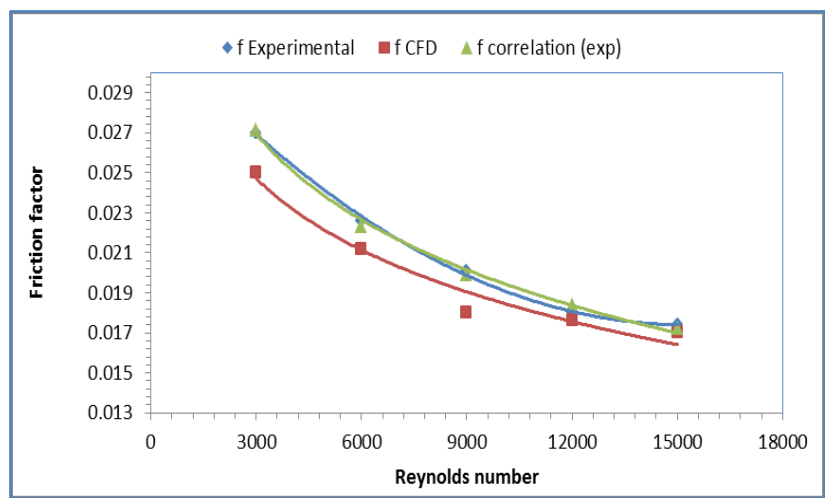

Fig.6 Comparison of experimental, CFD, and developed correlation of friction factor

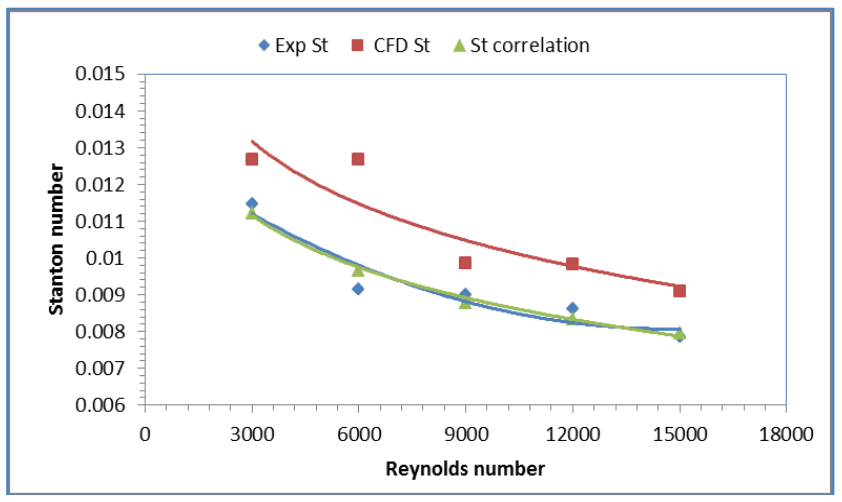

Fig. 7 Comparison of experimental, CFD, and developed correlation of Stanton number

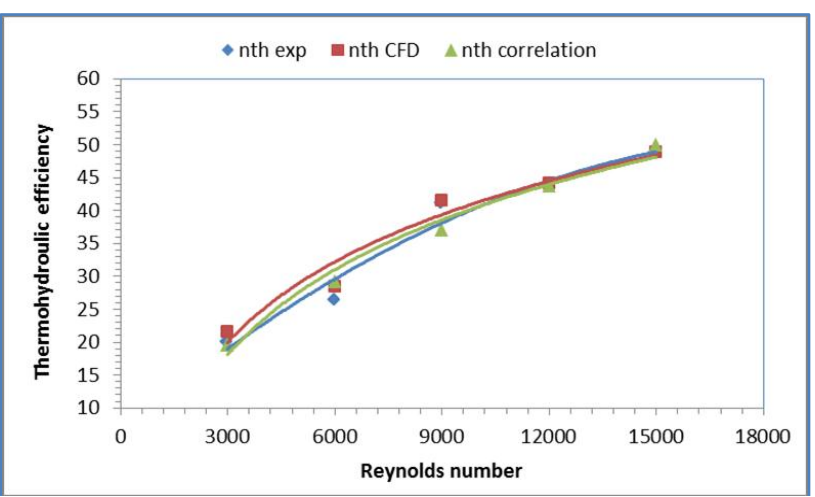

Fig. 8 Comparison of experimental, CFD and developed correlationof thermohydraulic efficiency

\section{References}

R. Karwa, S. C. Solanki, J. S. Saini, (1992), Heat transfer coefficient and friction factor correlations for the translational flow regime in rib-roughened rectangular duct, International Journal of Heat and Mass Transfer, 42, 1597-1615.

A. R. Jaurker, J. S. Saini, B. K. Gandhi, (2006), Heat transfer and friction characteristics of rectangular solar air heater duct using rib-grooved artificial roughness, Solar Energy, 2006, 80, pp. $895-907$.

P. Dhiman, N. S. Thakur, S. R. Chauhan, (2012),Thermal and thermohydraulic performance of counter and parallel flow packed bed solar air heaters, Renewable Energy, 46, 259 268.

J. L. Bhagoria, J. S. Saini, S. C. Solanki, (2002), Heat transfer coefficient and friction factor correlations for rectangular solar air heater duct having transverse wedge shaped rib roughness on the absorber plate, Renewable Energy, 25, 341-369.

V. S. Hans., R. P.Saini, J. B. Saini, (2010), Heat transfer and friction factor correlations for a solar air heater duct roughened artificially with multiple v-ribs, Solar Energy, 84, 898-911.

S. K. Saini, R. P. Saini, (2008), Development of correlation for Nusselt number and friction factor for solar air heater with roughened duct having arc-shaped wire as artificial roughness, Solar Energy, 82, 1118-1130.

N. S. Thakur, J. S. Saini, S. C. Solanki, (2003), Heat transfer and friction factor correlations for packed bed solar air heater for a low porosity system., Solar Energy, 74, 319-329.

C. D.Ho, C. S. Lin, Y. C. Chuang, C. C. Chao, (2013), Performance improvement of wire mesh packed doublepass solar air heaters with external recycle, Renewable energy, 57, 479-489.

A. Kumar, J. C. Saini, R. P. Saini, (2013), Development of correlations for Nusselt number and friction factor for solar air heater with roughened duct having multi vshaped with gap rib as artificial roughness, Renewable Energy, 58, 151-163.

R. L. Webb, (1972), Generalized heat transfer and friction factor correlations for tube with repeated-rib roughness, International Journal of Heat and Mass transfer, 1, 180-184.

T. Alam, R. P. Saini, J. S. Saini, (2014), Effect of circularity of perforation holes in V-shaped blockage on heat transfer and friction characteristics of rectangular SAH duct, Energy Conservation and Management, 86, 952-963.

L. Varshney, J. S. Saini, (1998), Heat transfer and friction factor correlations for rectangular solar air heater duct packed with wire mesh screen matrices, Solar Energy, 62 , 255-262.

R. Singh, R. P. Saini, J. S. Saini, (2006), Nusselt number and friction factor correlations for packed bed solar energy storage system having large sized elements of different shapes, Solar energy, 80, 760-771.

K.Sopian, M. A. Alghoul, A. M. Ebrahim, M. Y. Sulaiman, E. A.Musa, (2009), Evaluation of thermal efficiency of doublepass solar collector with porous-nonporous media, Renewable Energy, 34, 640-645. 